\title{
Enzalutamide: a new prostate cancer targeted therapy against the androgen receptor
}

\author{
Martín Lázaro Quintela ${ }^{\mathrm{c}}$, Luis León Mateos ${ }^{\mathrm{d}}$, Sergio Vázquez Estévez ${ }^{\mathrm{a}}$, Ovidio \\ Fernández Calvo ${ }^{\mathrm{f}}$, Urbano Anido Herranz ${ }^{\mathrm{e}}$, Francisco Javier Afonso Afonso ${ }^{\mathrm{g}}$, \\ Lucía Santoméb $^{\mathrm{b}}$ Luis Antón Aparicio ${ }^{\mathrm{h}}$
}

${ }^{a}$ Servicio de Oncología Médica, Hospital Universitario Lucus Augusti, C/Doutor Ulises Romero, s/n, 27003 Lugo, Spain

${ }^{b}$ Servicio de Oncología Médica, Hospital Povisa, C/Salamanca 5, 36211 Vigo, Spain

${ }^{c}$ Oncología Médica, Complexo Hospitalario Universitario de Vigo, C/Pizarro 22, 36204 Vigo, Spain

${ }^{d}$ Servicio de Oncología Médica, Complexo Hospitalario Universitario de Pontevedra, Spain

e Oncología Médica, Complejo Hospitalario Universitario de Santiago de Compostela, c/Choupana s/n, 15706 Santiago de Compostela, A Coruña, Spain

${ }^{f}$ Servicio Oncologia Medica, Complejo Hospitalario Universitario Ourense, C/Ramón Puga 54.32005, Spain

${ }^{g}$ Oncología Médica, C.H.U.Ferrol, Ferrol, A Coruña, Spain

${ }^{h}$ Medical Oncology Service, CHUA Coruña, Spain

\begin{abstract}
Enzalutamide (MDV3100), an androgen receptor-signalling inhibitor, represents the most recent compound added to the therapeutic armamentarium for the treatment of metastatic castration-resistant prostate cancer (mCRPC) who progressed to docetaxel. The anti-tumour activity and safety of enzalutamide has been demonstrated in a phase III clinical trial, showing a benefit in overall survival, which was the primary endpoint. There are no head-to-head studies comparing the different treatment options in this subset of patients. In this article, most relevant data published in the literature have been reviewed, with special attention to the therapeutic alternatives currently available for postdocexatel mCRPC patients, emphasising the mechanisms of action of the different drugs, efficacy and quality of life-related aspects.
\end{abstract}

\section{Keywords}

Enzalutamide; Metastatic castration-resistant prostate cancer; Abiraterone; Cabazitaxel; Docetaxel 


\section{Introduction}

Docetaxel combined with prednisone is currently the treatment of choice in patients with disseminated castration-resistant prostate cancer (CRPC). The option of docetaxel plus prednisone in advanced CRPC was approved in 2004 after publication of two independent phase III randomised studies showing an improvement in overall survival and quality of life in this group of patients [1], [2]. Thereafter, a better knowledge of the mechanisms of resistance and androgen production-related signalling pathways made possible the synthesis of new drugs with different mechanisms of action, including chemotherapeutic agents (cabazitaxel) [3] and agents with antiandrogenic activity (abiraterone acetate and enzalutamide) [4], [5], [6], all of which have demonstrated an increase in survival after disease progression on docetaxel.

This article presents a review of the different mechanisms of action of these drugs, with a particular focus on enzalutamide (MDV3100) because of its pharmacological characteristics, toxicity profile and health-related quality of life benefits in patients with prostate adenocarcinoma who had been treated with docetaxel.

\section{Comparative analysis of the mechanisms of action}

The development of CRPC is characterised by progression of the disease despite serum testosterone levels in the range of castration. There is increasing evidence of CRPC dependence on the androgen-receptor (AR) signalling pathway and underlying mechanisms. Androgen receptor expression is maintained throughout prostate cancer progression. Adrenal and intra-tumour androgens are an important source of AR activation. Other mechanisms resulting in permanent activation of $\mathrm{AR}$ include amplification and overexpression of the AR gene, AR mutations reducing ligand-binding specificity, activation of alternative Ras/Raf/MEK/ERK or Src and Ack1 thyrosine kinase pathways, altered levels of proteins promoting co-activation of AR and constitutively active AR splice variants [7].

The taxanes are microtubule-stabilising agents. Microtubules, key components of the cytoskeleton, are crucial in the development and maintenance of cell shape, in the transport of vesicles, traffic of transcription factors, mitochondrial function, cell signalling and cell division and mitosis. Taxanes are known to have a role in the separation of chromosomes during mitosis preventing transition from metaphase to anaphase and promoting apoptosis [8], [9]. Also, taxanes inhibit anti-apoptotic function of the Bcl-2 family proteins [9], [10] and activate cyclin-dependent kinase inhibitor 1A (p21, Cip1) and p53 protein in cancer cells causing cell cycle arrest and apoptotic cell death [11]. Taxanes may also have a direct effect on androgenic signalling pathway in prostate cancer. The microtubule stabilising activity of taxanes leads to AR cytoplasmic sequestration and subsequent inhibition of transcription activity in response to androgens or other ligand-independent pathways [12], [13]. In addition, it has been shown that taxanes induce nuclear accumulation of FOXO1, which is a known AR suppressive nuclear factor [14]. It is possible that taxane inhibition of the AR signalling pathway may be more relevant than the anti-mitotic activity, which may explain why taxanes are the only chemotherapeutic agents with a beneficial effect on survival in prostate cancer. Cabazitaxel overcomes one of the mechanisms of resistance of other taxanes due to poor affinity for the p-glycoprotein drug efflux pump, a major mechanism of resistance to docetaxel [12].

Abiraterone, the active metabolite of abiraterone acetate, is an irreversible inhibitor of CYP17A1 [15], the $17 \alpha$-hydroxilase and $C_{17,20}$-lyase enzymatic activity of which is essential for androgen biosynthesis [16]. Pregnenolone and progesterone are converted to 17 $\alpha$ hydroxipregnenolone and $17 \alpha$-hydroxiprogesterone by the $17 \alpha$-hydroxilase activity of CYP17A1, and then to dehydroepiandrosterone (DHEA) and androstenodione by $\mathrm{C}_{17,20}$-lyase activity. DHEA and androstenodione are precursors of testosterone [16]. CYP17A1 is expressed in testicular, adrenal and prostate tumour tissue. The expression of CYP17A1 in castration-resistant metastases has been reported to be 16.9 times higher than in the primary tumour [17]. Abiraterone requires the concurrent use of low-dose corticosteroids to inhibit ACTH stimulation and subsequent increase of 
mineralocorticoids and prevent secondary effects, such as fluid retention, hypokalemia and hypertension.

Enzalutamide has a much higher affinity for the AR receptor than first-generation antiandrogens [7], with no agonist activity and demonstrates activity even in case of amplification and overexpression of the AR, which are well known mechanisms involved in androgenic castration resistance [18]. Enzalutamide inhibits the AR signalling pathway and is a competitor inhibitor of dihydrotestosterone (DHT), the active metabolite of testosterone. In contrast to firstgeneration antiandrogens, enzalutamide also inhibits nuclear translocation of DHT-AR complex, remaining a significant fraction of AR in the cytoplasm and interfering directly in AR-mediated DNA transcription [18]. This clear differentiating mechanism results in a reduction of prostate cancer cell proliferation and an increase in cell death. Enzalutamide has also shown activity in AR splice variants lacking the ligand binding domain, a further known mechanism of castrate resistance, although detection of AR-V7 in circulating tumour cells may be associated with resistance to enzalutamide and abiraterone [19]. Therefore, in contrast to the ligand-dependent activity of abiraterone (adrenal and intratumoral residual androgens) in CRPC, enzalutamide acts on ligand-dependent resistance mechanisms (AR amplification) as well as ligand-independent resistance mechanisms (AR splice variants) (Fig. 1).

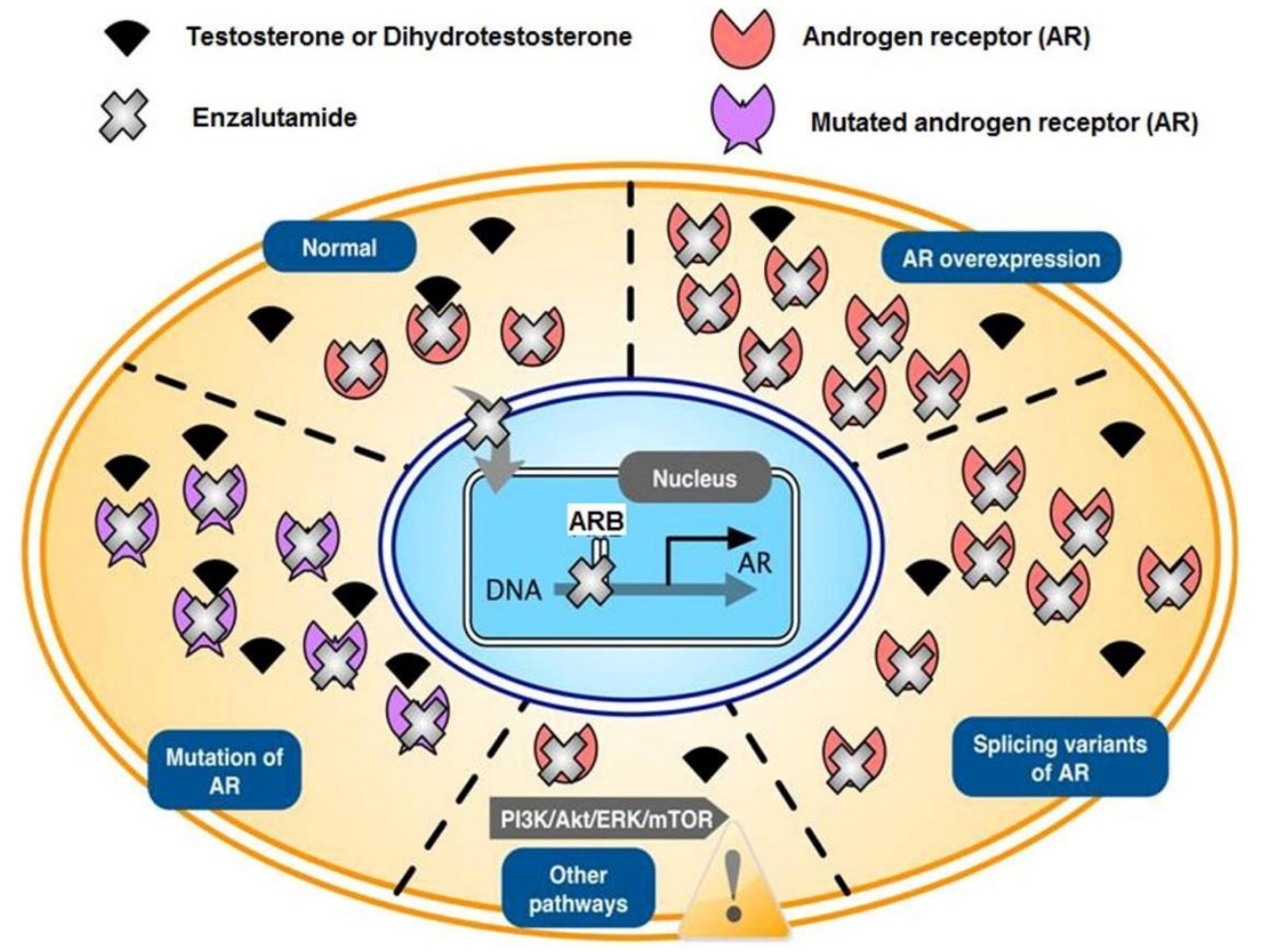

Fig. 1. Mechanism of action of enzalutamide (ARB: androgen receptor binding).

Unlike abiraterone, concomitant steroids are not needed because enzalutamide lacks the detrimental effects of mineralocorticoids excess. 
Despite the different mechanisms of action of enzalutamide and abiraterone, there is some scientific evidence of a possible interaction between taxanes and hormonal therapy based on preclinical data suggesting that androgen ablation, although effective in the control of the prostate tumour size, may increase the possibility of metastases and castration resistance by promoting epithelial mesenchymal transition (EMT) [20]. Androgen deprivation also increases ZEB1 transcription factor levels, a direct regulator of EMT related to taxane resistance [21].

Clinical data mostly based on retrospective studies with a small number of patients also indicate that androgen-deprivation therapies may reduce the efficacy of subsequent treatments with taxanes [22], [23], [24]. Studies suggesting a possible cross resistance between enzalutamide and abiraterone are also retrospective with a limited number of patients [25], [26]

\section{Clinical development of enzalutamide}

Before the use of enzalutamide in phase I-II studies, the effect of this drug was studied on CRPC xenograft models. Enzalutamide showed the ability to inhibit AR signalling in the overexpression of AR cells with high binding affinity to the AR and lack of agonist activity [18], [27]. Enzalutamide bound to the AR in a castration-resistant LNCaP/AR human prostate cancer cell model showing an eight-fold greater affinity than bicalutamide. Also, enzalutamide induced regression of established LMCaP/AR xenograft tumour cells, which overexpress ARs growing in castrated male mice [18], [27]. These data demonstrated the activity of enzalutamide and allowed the development of subsequent clinical studies.

A phase I-II study was conducted by Scher et al. [28] to assess the antitumour activity and efficacy of enzalutamide in patients with progressive metastatic CRPC (mCRPC). In this study, 140 patients were enrolled in dose-escalation cohorts of 3-6 patients starting with $30 \mathrm{mg}$ dose. The final doses studies were $30 \mathrm{mg}(n=3), 60 \mathrm{mg}(n=27), 150 \mathrm{mg}(n=28), 240 \mathrm{mg}(n=29), 360 \mathrm{mg}$ $(n=28), 480 \mathrm{mg}(n=22)$ and $600 \mathrm{mg}(n=3)$. Decreases in prostate specific antigen (PSA) levels were seen at all doses, in both chemotherapy-naïve and chemotherapy-treated patients, with a PSA decline of $50 \%$ or more in $56 \%$ of patients. Partial responses were observed in 13 (22\%) out of 59 patients with soft tissue metastases. The median time to radiological progression was 47 weeks. The maximum tolerated dose was $240 \mathrm{mg}$, with fatigue as the most frequent adverse event (grade $3-4$ in $11 \%$ of patients). The subsequent lower level $(150 \mathrm{mg})$ was established as the dose to be used in further studies, although the final commercialised dose was $160 \mathrm{mg}$. This study also assessed AR binding in vivo in 22 patients using 16 beta[18F]-fluoro-5 alpha-dihydrotestosterone (FDHT) positron emission tomography (PET) scans to measure change in FDHT uptake before and after starting treatment. All patients showed a clear reduction in FDHT uptake (range approximately 20-100\%).

In the landmark phase III, double-blind, placebo-controlled AFFIRM (A Study Evaluating the Efficacy and Safety of the Investigational Drug MDV3100) trial [6], 1199 men with castrationresistant prostate cancer with $\leqslant 2$ prior chemotherapy regimens, including $\geqslant 1$ containing docetaxel, were randomly assigned in a 2:1 ratio, to receive oral enzalutamide at a dose of $160 \mathrm{mg}$ per day (800 patients) or placebo (399 patients). Corticosteroids administration was optional in both arms. At a planned interim analysis after 520 death events, enzalutamide was superior to placebo in the primary endpoint, overall survival (hazard ratio [HR] for death $0.63,95 \%$ confidence interval [CI] $0.53-0.75, P<0.001)$. On the basis of these results, an independent data and safety monitoring committee recommended that the study be halted and unblinded, with eligible patients in the placebo group offered treatment with enzalutamide. An additional analysis has been done based on data cut-off of 29-June-2012, when 734 events had been reported (61.2\% of the total study population). Again, results remain in the same line: HR 0696 (95\% CI: 0.599 0.809 ) and a difference of 4.9 months in median time to death was observed. Enzalutamide was also superior over placebo with respect to all secondary endpoints, including reduction in PSA level by $50 \%$ or more $(54 \%$ vs. $2 \%, P<0.001)$; the soft-tissue response rate $(29 \%$ vs. $4 \%$, $P<0.001)$; the quality of life response rate $(43 \%$ vs. $18 \%, P<0.001)$; the time to PSA progression (8.3 vs. 3.0 months, HR $0.25, P<0.001)$; radiographic progression-free survival $(8.3 \mathrm{vs}$. 
2.9 months, HR $0.40, P<0.001)$ and the time to the first skeletal-related event $(16.7 v s$. 13.3 months, HR $0.69, P<0.001)$.

Enzalutamide has a good toxicity profile. The different target of enzalutamide and the lack of need to use concomitant steroids are likely to offer some potential advantages over abiraterone in terms of adverse events. In fact, a post hoc analysis of the AFFIRM trial found that on-study use of corticosteroids led to worse outcomes regardless of whether patients were randomly assigned to enzalutamide or placebo [29]. Median survival for on-study corticosteroid users was 12.8 months for the enzalutamide arm vs. 9.6 months for placebo $(P<0.001)$. For those not taking corticosteroids, the median survival was not yet reached in enzalutamide-treated patients vs. 18.8 months for placebo $(P<0.001)$. The benefit of enzalutamide compared to placebo was seen in both corticosteroid- and non-corticosteroid-treated patients. Median progression-free survival for enzalutamide and placebo was 5.6 vs. 2.9 months, respectively, in on-study corticosteroid users, and 11.1 vs. 3 months in patients who did not use corticosteroids $(P<0.001$ for both comparisons). Median time to PSA progression in on-study corticosteroid users was 5.6 months for enzalutamide and 3.1 months for placebo $(P<0.001)$ and 8.6 vs. 2.9 months, respectively $(P<0.001)$ among non-users. Use of on-study corticosteroids was associated with higher rates of grade 3 and 4 adverse events, including anaemia, fatigue, spinal cord compression and back pain. These results should be interpreted with caution, since this was a retrospective analysis, groups were not well balanced and the inferior outcomes in corticosteroid-treated patients may be due to unmeasured confounders or the biological properties of corticosteroid use itself.

Abiraterone has also been tested in MCRPC patients with ECOG PS $<2$ progression after docetaxel (phase III trial COU-AA-301) [4], [5]. Patients were randomized to either abiraterone plus prednisone or placebo plus prednisone. OS was increased with abiraterone treatment (15.8 months vs. 11.2 months; HR: 0.74; 95\% CI: 0.64-0.86; $P<0.0001$ ). Benefits were similar for all secondary endpoints. Several grade 3-4 toxicities were more frequent in patients treated with abiraterone, including fluid retention (4\% vs. $1 \%$ ), hypertension (1\% vs. $0 \%$ ) and cardiac disorders ( $4 \%$ vs. $2 \%)$.

In the phase III PREVAIL study [30], enzalutamide was compared to placebo in the predocetaxel setting. In a planned interim analysis, more than 1700 men with (mCRPC) that have progressed despite androgen deprivation therapy and chemotherapy naïve were analysed. Patients treated with enzalutamide demonstrated a statistically significant overall survival advantage compared with patients treated with placebo $(P<0.0001)$. Enzalutamide provided a $30 \%$ reduction in the risk of death compared with placebo (HR 0.70, 95\% CI 0.59-0.83). Moreover, there was a statistically significant radiographic progression-free survival advantage compared with placebotreated patients $(P<0.0001)$ [30]. Enzalutamide provided an $81 \%$ reduction in the risk of radiographic progression or death versus placebo (HR $0.19,95 \%$ CI $0.15-0.23$ ). Also, patients on treatment with enzalutamide showed a delay of 17 months in time to initiation of subsequent as compared to patients treated with placebo $(28.0 \mathrm{vs}$. 10.8 months, HR $0.35, P<0.0001)$. A total of $58.5 \%$ of enzalutamide-treated patients, most of them with soft tissue metastatic disease, showed complete or partial response as compared to $5 \%$ in placebo-treated patients. Before final database block, seizure events were not reported in the enzalutamide group as compared with one seizure event in the placebo group. A seizure event was notified in the enzalutamide group after database block and unblinding [30].

The efficacy of enzalutamide in three subsets of patients was assessed in subgroup analyses of the AFFIRM study, including elderly patients, patients with visceral metastases and long-term responders. In relation to elderly patients, older patients accounted for 25\% (199/800) and $26 \%$ (104/399) of enzalutamide- and placebo-treated patients, respectively. Improved outcomes with enzalutamide treatment were observed in both elderly and younger patients, with similar safety profiles in each age group [31]. In patients $\geqslant 75$ years of age, the median overall survival was 18.2 months in the enzalutamide arm as compared to 13.3 months in the placebo arm (HR 0.60, $95 \%$ CI $0.43-0.86, P=0.004)$. In patients $<75$ years, the median overall survival was not met (NM) for enzalutamide vs. 13.6 months for placebo (HR $0.63,95 \%$ CI $0.52-0.78, P<0.0001$ ). Safety and tolerability data were comparable between the two age groups. 
In patients with visceral metastases [32], including liver metastases $(11.5 \%$ [92/800] in the enzalutamide group and $8.5 \%$ [34/399] in the placebo group) and lung metastases (15.3\% [122/800] in the enzalutamide group and $14.8 \%$ [59/399] in the placebo group), the median overall survival in patients with liver and/or lung metastatic disease was 11.4 months (enzalutamide 13.4 months, placebo 9.5 months; HR 0.78 (95\% CI 0.56-1.09). Improved outcomes with enzalutamide were observed in both liver and lung mCRPC patients.

A total of $35 \%(276 / 800)$ of patients treated with enzalutamide were on therapy for $>12$ months and $22 \%(174 / 800)$ for $>18$ months [33]. When the long-term responder (LTR) subgroup was compared to the whole group of enzalutamide-treated patients, the median survival was longer (7.9 vs. 5.9 years) and had lower disease burden at baseline. Also, 50\% PSA response was $87 \%$ in the LTR subgroup and $54 \%$ in the whole enzalutamide group.

Small clinical series of patients have been reported in which the clinical activity of abiraterone acetate was evaluated in mCRPC progressing after enzalutamide [25], [26] as well as the activity of enzalutamide in patients pre-treated with docetaxel and abiraterone [34], [35], [36], [37]. Data of these studies are summarised in Table 1.

Table 1. Sequential treatment with enzalutamide and abiraterone in mCRPC.

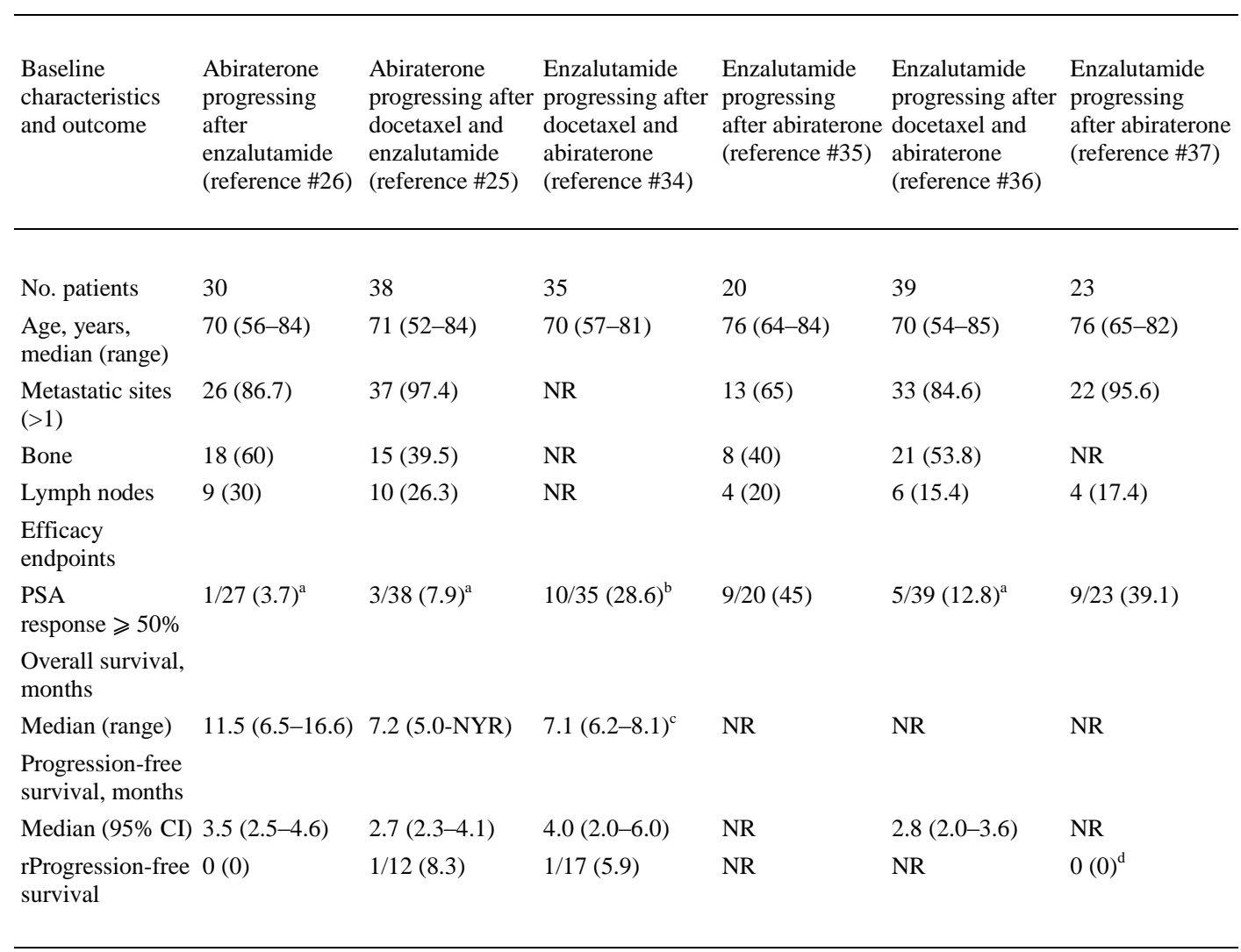

Abbreviations: NR: not reported; PSA: prostate-specific antigen; NYR: not yet reached; rProgression: radiographic progression.

${ }^{\text {a }}$ PSA response defined as $\geqslant 50 \%$ decline in PSA confirmed after $\geqslant 4$ weeks.

${ }^{\mathrm{b}}$ PSA response defined as $>50 \%$ decline in PSA.

${ }^{\mathrm{c}}$ Overall survival calculated as mean.

d A trend for improved radiographic progression-free survival in patients sensitive to abiraterone (15.7 vs. 11.4 weeks, $P=0.40)$. 


\section{Toxicity of enzalutamide}

Enzalutamide has a favourable toxicity profile. In the phase I-II study [28], fatigue was the most common adverse effect, requiring dose reduction in $11 \%$ of patients treated with a daily dose of $240 \mathrm{mg}$ or higher (grade 3). Fatigue usually appears after 30 days of treatment. Other grade 3-4 toxicities were anaemia (3\%) and joint pain (2\%). Nausea, constipation, diarrhoea and anorexia were mild adverse effects. The percentage of patients who discontinued enzalutamide treatment was $13 \%$ in those treated with doses of $360 \mathrm{mg} /$ day or higher, and $1 \%$ when the dose administered was $240 \mathrm{mg} /$ day or lower. Two of the 140 patients included in the study developed seizures at doses of 360 and $600 \mathrm{mg} /$ day, respectively; another patient possibly had seizures at a dose of $480 \mathrm{mg} /$ day. The two patients with seizures were also receiving concomitant medication that reduced the threshold for seizures. Other causes of treatment withdrawal were skin rash (2 patients) and a myocardial infarction in a patient with a metabolic syndrome.

In the phase III clinical trial [6], the rate of adverse events was similar in the enzalutamide and placebo arms, with a lower incidence of adverse events (grade $<3$ ) in the enzalutamide group (45\% vs. 53\%) as compared with placebo. The time elapsed from starting treatment to the first adverse event was 12.6 months and 4.2 months in the enzalutamide and placebo groups, respectively. The incidence (any grade) of fatigue (34\%), diarrhoea (21\%), hot flashes (20\%), musculoskeletal pain $(14 \%)$ and headache $(12 \%)$ was higher in the enzalutamide arm. Cardiac disorders were observed in $6 \%$ of patients and hypertension in $6.6 \%$ among enzalutamide-treated patients versus $8 \%$ and $3.3 \%$, respectively, among placebo-treated patients. Patients remained on treatment for a median of 8.3 months in the enzalutamide group and 3 months in the placebo group.

Of the 800 patients assigned to treatment with enzalutamide, seizures were recorded in 6 patients $(0.8 \%$ ) ( 4 of the seizures were witnessed), whereas no seizures were reported in the placebo group. One of the five patients had a status epilepticus that required medical intervention; in the remaining cases, seizures events were self-limited and did not recur after discontinuation of treatment. However, potential predisposing factors were present in four patients (two patients had brain metastases, one patient had inadvertently been administered lidocaine intravenously immediately before seizure and one patient with brain atrophy had an unwitnessed event classified as a seizure). A mechanism of inhibition of the $\gamma$-aminobutyric acid (GABA) related to the ligandgated ion channels of the $\mathrm{GABA}_{\mathrm{A}}$ receptor complex, decreasing the threshold for seizures has been postulated [38]. For this reason, enzalutamide should be used with caution in patients with history of seizures or predisposing factors, such as brain injury, stroke, cerebral metastasis, alcoholism or patients concomitantly treated with medications that may reduce the threshold for seizures (such as droperidol, lidocaine, bupropion, insulin, lithium, etc.) and, in these cases, treatment should be stopped if seizures occur. There is an ongoing study to assess the safety of enzalutamide in patients at risk of seizure events.

In the PREVAIL trial, incidence of hypertension and cardiac disorder in any grade were higher than in the AFFIRM study (13 vs. $6.6 \%$ and 10 vs. $6 \%$ respectively) [30], whereas the incidence of seizures happened less frequently in the PREVAIL trial (5 of 800 patients in AFFIRM, 1 of 871 patients in PREVAIL).

The most common adverse event recorded in three randomized clinical trials with the use of enzalutamide [6], abiraterone [4] and cabazitaxel [3] are shown in Table 2. 
Table 2. Adverse events recorded in three randomised studies of enzalutamide, abiraterone and cabazitaxel.

\begin{tabular}{|c|c|c|c|c|c|c|}
\hline \multirow[t]{2}{*}{ Adverse event } & \multicolumn{2}{|c|}{$\begin{array}{l}\text { Enzalutamide (AFFIRM study, } \\
\text { reference \#6) }\end{array}$} & \multicolumn{2}{|c|}{$\begin{array}{l}\text { Abiraterone (COU.AA-301 } \\
\text { study, reference \#4) }\end{array}$} & \multicolumn{2}{|c|}{$\begin{array}{l}\text { Cabazitaxel (TROPIC study, } \\
\text { reference \#3) }\end{array}$} \\
\hline & Any grade & Grade $\geqslant 3$ & Any grade & Grade $\geqslant 3$ & Any grade & Grade $\geqslant 3$ \\
\hline Anaemia & NR & NR & 23 & 7 & 97 & 11 \\
\hline Thrombocytopaenia & NR & NR & 4 & 1 & 47 & 4 \\
\hline Febrile neutropenia & NR & NR & 0 & 0 & 0 & 8 \\
\hline Arthralgia & NR & NR & 27 & 4 & 11 & 1 \\
\hline Fatigue & 34 & 6 & 44 & 8 & 37 & 5 \\
\hline Headache & 12 & 1 & NR & NR & NR & NR \\
\hline Diarrhoea & 21 & 1 & 18 & 1 & 47 & 6 \\
\hline Cardiac disorder & 6 & 1 & 13 & 4 & NR & \\
\hline Oedema/fluid retention & NR & NR & 31 & 3 & NR & NR \\
\hline Hypertension & 6.6 & & 10 & 1 & NR & NR \\
\hline Nauseas & NR & NR & 30 & 2 & 34 & 2 \\
\hline Liver dysfunction & 1 & $<1$ & 10 & 3 & NR & NR \\
\hline Seizures & $<1$ & $<1$ & & & & \\
\hline Urinary tract infection & NR & NR & 12 & 2 & 7 & 1 \\
\hline
\end{tabular}

NR: not reported.

\section{Symptomatic benefit and enzalutamide}

Secondary endpoints in the trials of enzalutamide included improvement in health-related quality of life, relief of pain and time to the first skeletal-related event. Improvement of the quality of life is a very relevant objective in the treatment of patients with mCRPC. The Functional Assessment of Cancer Therapy-Prostate (FACT-P) questionnaire is a reliable self-administrated scale for assessing health-related quality of life in patients with prostate cancer [40]. The FACT-P is a 39-item questionnaire on which the score for each item can range from 0 to 4 , with higher scores indicating a better quality of life.

In the pivotal randomised trial of enzalutamide [6], quality-of-life response (a secondary endpoint) was defined as a 10-point improvement in the global score on the FACT-P questionnaire, as compared with baseline, on two consecutive measurements obtained at least 3 weeks apart, and worsening as 10-point decrease. Patients with baseline and $\geqslant 1$ post-baseline evaluation were included in the analysis $(n=938)$ [41]. A greater percentage of patients on enzalutamide reported health-related quality of life improvement compared to placebo $(42.2 \% v s$. $14.5 \%, P<0.001$ ), with a median time to the first quality of life deterioration of 9.0 and 3.7 months for enzalutamide and placebo, respectively $(P<0.001)$. Overall, $46.8 \%$ of patients on enzalutamide and $59.3 \%$ on placebo experienced health-related quality of life deterioration at some point while on treatment $(P=0.001)$. The time to the first skeletal-related event (defined as pathological fracture, spinal cord compression or palliative radiation therapy or surgery to bone) was 16.7 vs. 13.3 months for the arms of enzalutamide and placebo, respectively (HR 0.69, $P<0.001)$.

In the AFFIRM trial [6], patients were stratified according to the baseline Eastern Cooperative Oncology Group (ECOG) performance status score and the Brief Pain Inventory-Short Form (BPI$\mathrm{SF})$ question 3 score addressing the average pain over the 7 days before randomisation $(0-3$ [no pain to mild pain] vs. $4-10$ [moderate-to-severe pain]). At baseline, $28 \%$ had a BPI-SF score $\geqslant 4$. Palliation of pain was defined as a decrease of $\geqslant 30 \%$ in the BPI-SF score on week 13 as compared 
to baseline, without an increase $\geqslant 30 \%$ in the use of analgesics. Palliation of pain was achieved by $45 \%$ of enzalutamide patients vs. $7 \%$ of placebo patients $(P=0.0079)$. Pain progression was recorded in $28 \%$ of patients treated with enzalutamide and in $39 \%$ of patients treated with placebo $(P=0.0018)[42]$.

In the COU-AA-301 randomised trial [39], secondary endpoints were pain control and skeletalrelated events. Pain intensity defined as item 3 of the BPI-SF in the past 24 hours. Patients with BPI-SF score $\geqslant 4$ at baseline were included in the analysis. Pain intensity palliation was defined according two consecutive follow-up visits (at least 4 weeks apart) at which the pain intensity score was at least $30 \%$ lower than that at baseline, without an increase in analgesic use (defined as $a \geqslant 1$ point increase on the $\mathrm{WHO}$ analgesic scale). Abiraterone acetate plus prednisone resulted in significantly more pain palliation than prednisone $(45 \%$ vs. $28.8 \%, P=0.0005)$. The median time to occurrence of first skeletal-event was also longer with abiraterone (25 vs. 20.3 months, $P=0.0001$ ). In a recent analysis [43], significant improvements in the FACT-P total score were observed in $48 \%$ of patients receiving abiraterone acetate plus prednisone $v$ s. $32 \%$ of patients receiving prednisone $(P<0.0001)$.

In the prednisone plus cabazitaxel or mitoxantrone for mCRPC (TROPIC study) [3], pain and analgesic was assessed with the McGill-Melzack present pain intensity (PPI) scale and analgesic use was derived from consumption normalised to morphine equivalents. Pain response rates were similar in the two groups $(7.7 \%$ mitoxantrone $v s .9 .2 \%$ cabazitaxel, $P=0.63)$.

\section{Future directions}

New questions currently arise in the context of androgen deprivation therapy and ARdependent tumours. Which is the best drug for starting treatment? Which drug combination improves efficacy or reverses resistance to other treatments? Is enzalutamide active in patients with other solid tumours? According to recent favourable results of enzalutamide obtained in the phase III PREVAIL study [30], enzalutamide is an option in the treatment of mCRPC before docetaxel. However, final analyses of the PREVAIL trial and data provided by other ongoing studies will contribute to define the better use of enzalutamide and other drugs in mCRPC.

At the present time, other studies of enzalutamide in the pre-chemotherapy setting have been registered, such as enzalutamide versus bicalutamide in castrate men with metastatic prostate cancer who have progressed while on while on luteinizing hormone receptor hormone (LHRH) agonist/antagonist or after receiving a bilateral orchiectomy (NCT01288911). This ongoing, headto-head, phase 2 clinical trial (TERRAIN study) [44] is the first to prospectively determine whether enzalutamide can provide improved antitumour effects $v$ s. bicalutamide in men with metastatic progressive CRPC (enrollment 375 patients). Enzalutamide vs. bicalutamide in men with prostate cancer who have failed after primary androgen deprivation therapy is also being evaluated in a phase II study (STRIVE), in which both metastatic and non-metastatic patients are eligible (enrollment 400 patients) (NCT01664923). Also, enzalutamide as neoadjuvant therapy is being assessed in combination with LHRH analogues (leuprolide and dutasteride) (NCT01547299) or with of abiraterone acetate and prednisone (NCT01946165, NCT01949337). In bone mCRPC, the combination of enzalutamide and abiraterone is going to be assessed in a phase II study (NCT01650194) as well as the combination of enzalutamide and docetaxel in advanced prostate cancer in a phase I study (NCT01565928).

In other hand, enzalutamide is being tested in combination phase I trials for metastatic castration-resistant prostate cancer patients with everolimus (NTC02125084) and crizotinib (NTC02207504). In phase II trials combining with tivozanib (NTC01885949), sipuleucel T (NTC01981122), Radium 223 (NTC02199197 and NTC02225704) or even PSA-TRICOM vaccine in combination with enzalutamide (NTC01875230). Interestingly, there is a phase II trial comparing Radium 223 alone against Radium 223 with abiraterone acetate or Radium 223 with enzalutamide in metastatic castration-resistant prostate cancer patients (NTC02034552). In some phase III trials other combinations are being tested, such as in the PEACE III trial, where 
enzalutamide alone is compared with enzalutamide with Radium 223 (NTC02194842) and the arm $\mathbf{J}$ in the STAMPEDE trial where they test the combination of antiandrogens deprivation therapy plus abiraterone acetate plus enzalutamide and prednisolone (NTC00268476).

Enzalutamide is also being studied in other tumours, such as in patients with advanced, androgen receptor-positive, triple negative breast cancer (NCT01889238) and in a phase I study of patients with incurable breast cancer (NCT01597193). A summary of these studies is shown in Table 3.

Table 3. Summary of registered clinical trials of enzalutamide in ClinicalTrials.gov.

\begin{tabular}{|c|c|c|c|}
\hline $\begin{array}{l}\text { ClinicalTrials.gov } \\
\text { identifier }\end{array}$ & Study & Treatment arms & Comments \\
\hline NCT0121299 & $\begin{array}{l}\text { Phase } \\
\text { III }\end{array}$ & $\begin{array}{l}\text { A: enzalutamide } \\
\text { B: placebo }\end{array}$ & Pre-chemotherapy \\
\hline NCT01288911 & $\begin{array}{l}\text { Phase } \\
\text { II }\end{array}$ & $\begin{array}{l}\text { A: enzalutamide } \\
\text { B: bicalutamide }\end{array}$ & $\begin{array}{l}\text { After LHRH analogue or bilateral surgical } \\
\text { orchiectomy }\end{array}$ \\
\hline NCT01547299 & $\begin{array}{l}\text { Phase } \\
\text { II }\end{array}$ & $\begin{array}{l}\text { A: enzalutamide } \\
\text { B: enzalutamide-leuprolide-dutasteride }\end{array}$ & Neoadjuvant \\
\hline NCT01946165 & $\begin{array}{l}\text { Phase } \\
\text { II }\end{array}$ & $\begin{array}{l}\text { A: abiraterone-LHRH analogue } \\
\text { B: enzalutamide-abiraterone-LHRH } \\
\text { analogue }\end{array}$ & Neoadjuvant \\
\hline NCT01949337 & $\begin{array}{l}\text { Phase } \\
\text { III }\end{array}$ & $\begin{array}{l}\text { A: enzalutamide } \\
\text { B: enzalutamide-abiraterone }\end{array}$ & Post-chemotherapy \\
\hline NCT01650194 & $\begin{array}{l}\text { Phase } \\
\text { II }\end{array}$ & Enzalutamide-abiraterone & Pre-chemotherapy \\
\hline NCT01565928 & Phase I & Enzalutamide-docetaxel & mCRPC \\
\hline NTC02125084 & Phase I & Enzalutamide-everolimus & mCRPC \\
\hline NTC02207504 & Phase I & Enzalutamide-crizotinib & mCRPC \\
\hline NTC01885949 & $\begin{array}{l}\text { Phase } \\
\text { II }\end{array}$ & Enzalutamide-tivozanib & mCRPC \\
\hline NTC01981122 & $\begin{array}{l}\text { Phase } \\
\text { II }\end{array}$ & Enzalutamide-sipuleucel T & mCRPC \\
\hline NTC02034552 & $\begin{array}{l}\text { Phase } \\
\text { II }\end{array}$ & $\begin{array}{l}\text { A: Radium } 223 \\
\text { B: Radium } 223 \text {-enzalutamide } \\
\text { C: Radium 223-abiraterone }\end{array}$ & mCRPC \\
\hline NTC01875230 & $\begin{array}{l}\text { Phase } \\
\text { II }\end{array}$ & $\begin{array}{l}\text { A: Enzalutamide } \\
\text { B: Enzalutamide-PSA-TRICOM }\end{array}$ & mCRPC \\
\hline NTC02194842 & $\begin{array}{l}\text { Phase } \\
\text { III }\end{array}$ & $\begin{array}{l}\text { A: Enzalutamide } \\
\text { B: Enzalutamide-Radium } 223\end{array}$ & mCRPC \\
\hline NTC00268476 & $\begin{array}{l}\text { Phase } \\
\text { III }\end{array}$ & $\begin{array}{l}\text { Antiandrogen deprivation therpy- } \\
\text { Enzalutamide-abiraterone }\end{array}$ & Arm J, STAMPEDE trial \\
\hline NTC02138383 & Phase I & Enzalutamide-nab-paclitaxel-gemcitabine & Pancreatic cancer \\
\hline NCT01889238 & $\begin{array}{l}\text { Phase } \\
\text { II }\end{array}$ & Enzalutamide & $\begin{array}{l}\text { Triple negative breast cancer, androgen } \\
\text { receptor-positive }\end{array}$ \\
\hline NCT01597193 & Phase I & Enzalutamide & Incurable breast cáncer \\
\hline
\end{tabular}




\section{Concluding remarks}

The AR signalling pathway is a crucial element in the natural history of mCRPC. Four drugs have been approved for this indication and are currently available for the treatment of patients with mCRPC progressing after docetaxel therapy: enzalutamide, abiraterone, cabazitaxel and RAD-223. The anti-tumour activity of the first three drugs is explained, at least in part, by the mechanism of action on the androgenic signalling pathway at the AR or the androgen precursors level. Enzalutamide has a much higher binding affinity to the AR than the other anti-androgenic drugs, and is without agonist properties. In contrast to abiraterone, enzalutamide acts through liganddependent and independent resistance mechanisms. Enzalutamide also lacks the detrimental effects of mineralocorticoid excess, so contrary to what occurs with abiraterone, concomitant administration of systemic corticosteroids is not needed. Health-related quality of life is an important goal in the treatment of an incurable disease such as mCRPC, so that the best treatment is probably that which allowing control of the disease together with a better and more effective control of symptoms with fewer adverse effects. In this respect, although measurements of quality of life cannot be extrapolated across different studies, results reported support that treatment of mCRPC has clinical benefits for the patient. In relation to drug-related adverse events, abiraterone and enzalutamide appear to be better tolerated, with the difference that in the case of enzalutamide, concurrent administration of corticosteroids is not necessary, so it does have the risk of corticosteroids-related complications. Finally, it should be pointed out that because of its mechanism of action, good tolerance and results of the PREVAIL study [30], several studies are being conducted aimed at positioning enzalutamide in other phases of the clinical evolution of mCRPC, as well as defining its role in combination with other active drugs for the treatment of this neoplasm.

\section{Conflict of interest}

All authors confirm that there is not any conflict of interest.

\section{Acknowledgement}

The authors thank Marta Pulido, MD, for editing the manuscript and editorial assistance.

\section{References}

[1] Tannock IF, de Wit R, Berry WR, et al. Docetaxel plus prednisone or mitoxantrone plus prednisone for advanced prostate cancer. N Engl J Med 2004;351:1502-12.

[2] Petrylak DP, Tangen CM, Hussain MH, et al. Docetaxel and estramustine compared with mitoxantrone and prednisone for advanced refractory prostate cancer. N Engl J Med 2004;351:1513-20.

[3] De Bono JS, Oudard S, Ozguroglu M, et al. Prednisone plus cabazitaxel or mitoxantrone for metastatic castration-resistant prostate cancer progressing after docetaxel treatment: a randomised open-label trial. Lancet 2010;376:1147-54.

[4] De Bono JS, Logothetis CJ, Molina A, et al. Abiraterone and increased survival in metastatic prostate cancer. N Engl J Med 2011;364:1995-2005.

[5] Fizazi K, Scher HI, Molina A, et al. Abiraterone acetate for treatment of metastatic castrationresistant prostate cancer: final overall survival analysis of COU-AA-301 randomised, doubleblind, placebo-controlled phase 3 study. Lancet Oncol 2012;13(10):983-92.

[6] Scher HI, Fizazi K, Saad F, et al. Increased survival with enzalutamide in prostate cancer after chemotherapy. N Engl J Med 2012;367:1187-97.

[7] Tsao CK, Galsky MD, Small AC, et al. Targeting the androgen receptor signalling axis in castration-resistant prostate cancer (CRPC). BJU Int 2012;110:1580-8.

[8] Jordan MA, Wilson L. Microtubules as a target for anticancer drugs. Nat Rev Cancer 2004;4:253-65.

[9] Moos PJ, Fitzpatrick FA. Taxanes propagate apoptosis via two cell populations with distinctive cytological and molecular traits. Cell Growth Differ 1998;9:687-97. 
[10] Li Y, Li X, Hussain M, Sarkar FH. Regulation of microtubule, apoptosis, and cell cycle-related genes by taxotere in prostate cancer cells analyzed by microarray. Neoplasia 2004;6:158-67.

[11] Komlodi-Pasztor E, Sackett D, Wilkerson J, Fojo T. Mitosis is not a key target of microtubule agents in patient tumors. Nat Rev Clin Oncol 2011;8:244-50.

[12] Darshan MS, Loftus MS, Thadani-Mulero M, et al. Taxane-induced blockade to nuclear accumulation of the androgen receptor predicts clinical responses in metastatic prostate cancer. Cancer Res 2011;71:6019-29.

[13] Zhu ML, Horbinski CM, Garzotto M, et al. Tubulin-targeting chemotherapy impairs androgen receptor activity in prostate cancer. Cancer Res 2010;70:7992-8002.

[14] Gan L, Chen S, Wang Y, et al. Inhibition of the androgen receptor as a novel mechanism of taxol chemotherapy in prostate cancer. Cancer Res 2009;69:8386-94.

[15] Mohler JL, Titus MA, Wilson EM. Potential prostate cancer drug target: bioactivation of androstanediol by conversion to dihydrotestosterone. Clin Cancer Res 2011;17:5844-9.

[16] Yamaoka M, Hara T, Kusaka M. Overcoming persistent dependency on androgen signaling after progression to castration-resistant prostate cancer. Clin Cancer Res 2010;16:4319-24.

[17] Montgomery RB, Mostaghel EA, Vessella R, et al. Maintenance of intratumoral androgens in metastatic prostate cancer: a mechanism for castration-resistant tumor growth. Cancer Res 2008;68:4447-54.

[18] Tran C, Ouk S, Clegg NJ, et al. Development of a second-generation antiandrogen for treatment of advanced prostate cancer. Science 2009;324:787-90.

[19] Antonarakis ES, Lu C, Wang H, Luber B, Nakazawa M, Roeser JC, et al. AR-V7 and resistance to enzalutamide and abiraterone in prostate cancer. New Engl J Med 2014;371:1028-38.

[20] Zhu ML, Kyprianou N. Role of androgens and the androgen receptor in epithelial-mesenchymal transition and invasion of prostate cancer cells. FASEB J 2010;24:769-77.

[21] Sun Y, Wang BE, Leong KG, et al. Androgen deprivation causes epithelial-mesenchymal transition in the prostate: implications for androgen-deprivation therapy. Cancer Res 2012;72:527-36.

[22] Mezynski J, Pezaro C, Bianchini D, et al. Antitumour activity of docetaxel following treatment with the CYP17A1 inhibitor abiraterone: clinical evidence for cross-resistance? Ann Oncol 2012;23:2943-7.

[23] Febbo PG, Richie JP, George DJ, et al. Neoadjuvant docetaxel before radical prostatectomy in patients with high-risk localized prostate cancer. Clin Cancer Res 2005;11:5233-40.

[24] Gravis G, Fizazi K, Joly F, et al. Androgen-deprivation therapy alone or with docetaxel in noncastrate metastatic prostate cancer (GETUG-AFU 15): a randomised, open-label, phase 3 trial. Lancet Oncol 2013;14:149-58.

[25] Loriot Y, Bianchini D, Ileana E, et al. Antitumour activity of abiraterone acetate against metastatic castration-resistant prostate cancer progressing after docetaxel and enzalutamide (MDV3100). Ann Oncol 2013;24:1807-12.

[26] Noonan KL, North S, Bitting RL, et al. Clinical activity of abiraterone acetate in patients with metastatic castration-resistant prostate cancer progressing after enzalutamide. Ann Oncol 2013;24:1802-7.

[27] Guerrero J, Alfaro IE, Gómez F, et al. Enzalutamide, an androgen receptor signaling inhibitor, induces tumor regression in a mouse model of castration-resistant prostate cancer. Prostate 2013;73:1291-305.

[28] Scher HI, Beer TM, Higano CS, et al. Antitumour activity of MDV3100 incastration-resistant prostate cancer: a phase 1-2 study. Lancet 2010;375:1437-46.

[29] Scher HI, Fizazi K, Saad F, et al. Impact of on-study corticosteroid use on efficacy and safety in the phase III AFFIRM study of enzalutamide (ENZA), an androgen receptor inhibitor. J Clin Oncol 2013;31(Suppl. 6):6.

[30] Beer TM, Armstrong AJ, Rathkopf Y, et al. Enzalutamide in metastatic prostate cancer before chemotherapy. N Engl J Med 2014;371:424-33.

[31] Sternberg DC, De Bono JS, Chi KN, et al. Outcomes in elderly patients with metastatic castration-resistant prostate cancer (mCRPC) treated with the androgen receptor inhibitor enzalutamide: results from the phase III AFFIRMtrial. J Clin Oncol 2013;31(Suppl. 6) [abstract $16]$.

[32] Loriot Y, Fizazi K, De Bono JS, et al. Outcomes in patients with liver or lung metastatic castration-resistant prostate cancer (mCRPC) treated with the androgen receptor inhibitor enzalutamide: results from the phase III AFFIRM trial. J Clin Oncol 2013;31(Suppl.) [abstract 5065].

[33] Fleming MT, Scher HI, Fizazi K, et al. Long-term responders to enzalutamide (ENZA) during the phase III AFFIRM trial: baseline characteristics and efficacy outcomes. J Clin Oncol 2013;31(Suppl. 6) [abstract 20].

[34] Schrader AJ, Boegemann M, Ohlmann CH, et al. Enzalutamide in castration-resistant prostate cancer patients progressing after docetaxel and abiraterone. Eur Urol 2014;65:30-6. 
[35] Bournakis E, Gyftaki R, Kafantari E, et al. Enzalutamide (ENZA) in heavily pretreated patients with bone metastatic castration resistant prostate cancer (mCRPC) resistant to androgen biosynthesis inhibitor (ABI) treatment - the Hellenic experience of the Name Patient Access Program (NPAP). The European Cancer Congress, Amsterdam, The Netherlands, 2013, abstract 2906.

[36] Bianchini D, Lorente D, Rodriguez-Vida A, et al. Antitumour activity of enzalutamide (MDV3100) in patients with metastatic castration-resistant prostate cancer (CRPC) pre-treated with docetaxel and abiraterone. Eur J Cancer 2014;50:78-84.

[37] Thomson D, et al. British Association of Urological Surgeons (BAUS), Newcastle, November 14-16, 2013.

[38] Treiman DM. GABAergic mechanisms in epilepsy. Epilepsy 2001;42(Suppl. 3):8-12.

[39] Logothetis CJ, Basch E, Molina A, et al. Effect of abiraterone acetate and prednisone compared with placebo and prednisone on pain control and skeletal-related events in patients with metastatic castration-resistant prostate cancer: exploratory analysis of data from the COU-AA301 randomised trial. Lancet Oncol 2012;13:1210-7.

[40] Esper P, Mo F, Chodak G, et al. Measuring quality of life in men with prostate cancer using the functional assessment of cancer therapy-prostate instrument. Urology 1997;50:920-8.

[41] Miller K, Scher HI, Fizazi K, et al. Effect of enzalutamide on health-related quality of life (HRQoL) in men with metastatic castration-resistant cancer (mCRPC) following docetaxelbased therapy: results from the AFFIRM study. J Clin Oncol 2013;31(Suppl. 6) [abstract 17].

[42] Fizazi K, Scher HI, Saad F, et al. Impact of Enzalutamide, an androgen receptor signaling inhibitor, on time to first skeletal related event (SRE) and pain in the phase 3 AFFIRM Study. Ann Oncol 2012;23(Suppl. 9) [abstract 8960].

[43] Harland S, Staffurth J, Molina A, et al. Effect of abiraterone acetate treatment on the quality of life of patients with metastatic castration-resistant prostate cancer after failure of docetaxel chemotherapy. Eur J Cancer 2013;49:3648-57.

[44] Baskin-Bey ES, Shore ND, Barber K, et al. TERRAIN: A randomized, double-blind, phase II study comparing MDV3100 with bicalutamide (Bic) in men with metastatic castrate-resistant prostate cancer (CRPC). J Clin Oncol 2012;30(Suppl.) [abstract TPTPS4698]. 